\author{
Agnieszka Christenheit ${ }^{1 \star}$, Petra \\ Heffeter ${ }^{2}$ and Edgar Selzer ${ }^{1,3}$ \\ ${ }^{1}$ Department of Radiation Oncology, Medical \\ University of Vienna, Waehringer Guertel 18-20, \\ 1090 Vienna, Austria \\ ${ }^{2}$ Department of Internal Medicine I, Institute of \\ Cancer Research, Medical University of Vienna \\ Borschkegasse 8a, 1090 Vienna, Austria \\ ${ }^{3}$ Institute for Radiation Oncology, Hospital Wiener \\ Neustadt, Corvinusring 3, 2700 Wiener Neustadt, \\ Lower Austria, Austria
}

Dates: Received: 12 March, 2016; Accepted: 17 March, 2016; Published: 18 March, 2016

*Corresponding author: Prof. Dr. Edgar Selzer, Department of Radiation Oncology, Medical

University of Vienna, Waehringer Guertel 18-20,

A-1090 Vienna, Austria, Tel: ++43-1-40400 26920;

E-mail: edgar.selzer@meduniwien.ac.at

www.peertechz.com

Keywords: Integrin antagonists; $\alpha \mathrm{V} \beta 3$; Anoikis; Inhibition of angiogenesis; Cancer

\section{Research Article \\ A Novel Small-Molecule Integrin Antagonist Inhibits Cells Adhesion Followed By Anoikis in Endothelial Cells - A Comparative Analysis with Cilengitide}

\begin{abstract}
Background: Despite the crucial role of integrin receptors in cancer pathogenesis and massive efforts towards establishing clinically relevant drugs, to the present no effective integrin antagonist for the treatment of malignant diseases has been introduced into the clinic.

Context and purpose of the study: The purpose of the study was to examine the cellular effects and molecular mechanisms of a novel anti-integrin compound designated AV-398/38 and to compare it with cilengitide, one of the most advanced and best characterized $\alpha \vee \beta 3 / \alpha \vee \beta 5$ integrin antagonists. AV-398/38 is a small molecule integrin antagonist that is currently in an early phase of pre-clinical evaluation. It was identified by virtual screening of chemical databases with the aim to detect novel integrin $\alpha \vee \beta 3$ antagonist-like candidates. Based on preliminary in vitro data, the compound was recognized as a potential anti-neoplastic drug candidate, displaying high specificity and binding affinity in the nanomolar range towards the $\alpha \mathrm{V} \beta 3$ receptor, as well as showing potentially favorable drug-like properties.

Results: Our studies revealed that its anti-neoplastic properties are most likely mediated by inhibition of integrin-mediated cell attachment to the extracellular matrix resulting in anoikis in a TP53 independent manner. Additionally, we observed inhibition of integrin-linked pathways involved in cell proliferation, survival and migration such as FAK, Akt, and MAPK as well as direct inhibitory effects on cell migration. We compared the effects of the compound with cilengitide, which is one of the bestcharacterized $\alpha \vee \beta 3$ antagonists available.
\end{abstract}

Main findings: The main finding was the observation, that AV-398/38 is capable of inducing cell death via induction of anoikis in a TP53 independent manner.

Conclusions: Integrin $\alpha \vee \beta 3 / \alpha \vee \beta 5$ inhibition leads to apoptotic cell death most likely triggered by a loss of adherence.

Brief summary and potential implications: Our data indicate that compound AV-398/38 or structurally similar molecules may be promising candidates for preclinical development.

\section{Introduction}

During the past decades immense efforts have been made to identify relevant targets for cancer treatment. Attempts to establish effective therapeutic strategies have drawn the attention to a large family of cell surface receptors, the so-called integrins. Integrins are adhesion molecules that mediate interactions between cells and the extracellular environment with the cytoskeleton, thereby controlling survival, proliferation, migration and invasion [1-3]. The structure of integrin, their pattern of activity and a broad array of biological functions, as well as their involvement in the pathophysiology of disorders such as thrombosis, inflammation, autoimmune diseases or cancer, provided appealing prospects for the development of effective antagonists [4]. Major approaches focused on modulating integrin expression by direct blockage of ligand binding or inhibition of downstream signaling with small molecules, peptides or engineered antibodies. Initial attempts to develop pharmacologically potent anti-integrin drugs resulted in approval of abciximab (ReoPro ${ }^{\circledR}$ ), eptifibatide (Integrilin ${ }^{\circledR}$ ) and tirofiban $\left(\right.$ Aggrastat $\left.^{\circledR}\right)$. These compounds target $\alpha \operatorname{IIb} \beta 3$ integrin that plays a crucial role in platelet aggregation [5]. Natalizumab $\left(\right.$ Tysabri $^{\circledR}$ ) and efalizumab (Raptiva ${ }^{\circledR}$ ) which inhibit $\alpha 4$ and $\alpha \mathrm{L} \beta 2$ integrins, respectively, were introduced into the clinic as agents against autoimmune disorders such as multiple sclerosis, Crohn's disease, and psoriasis. However, severe side effects ultimately led to the withdrawal of efalizumab [5]. Additional efforts were directed towards targeting other types of integrins in cancer focussing mainly on $\alpha 5 \beta 1, \alpha \mathrm{V} \beta 5$ and $\alpha \mathrm{V} \beta 3$ receptors regulating crucial processes in carcinogenesis such as adhesion, survival, migration, invasion and angiogenesis Desgrosellier and Cheresh [6]. Several promising integrin antagonists such as cilengitide, etaracizumab and volociximab reached a late stage of clinical evaluation in malignant melanoma, glioblastoma, non-small-cell lung cancer, pancreas, ovarian and prostate cancer [7-10]. Despite the remarkable number 
of currently investigated integrin antagonists, to the present none of the compounds has been approved for clinical use as an anti-cancer agent.

As has been mentioned above, preliminary results indicated that compound AV-38/398 might be a new promising small molecule anti-integrin candidate for use in cancer. Like cilengitide, it was designed to target primarily integrin $\alpha \mathrm{V} \beta 3$ and $\alpha \mathrm{V} \beta 5$ [11]. However, detailed molecular and biological studies have not been done. In the present study, we assessed several cellular effects and the underlying molecular mechanisms induced by compound AV-38/398 in primary endothelial and cancer cells. Another aim was to compare molecular and biological effects of this compound with cilengitide.

\section{Materials and Methods}

\section{Compounds and substances}

Synthesis of AV-398/38 (4- $(\{(Z)-5-[(Z)-3-E t h o x y-4-$ hydroxybenzylidene]-3-methyl-4-oxo-1,3-thiazolidin-2-ylidene amino)benzoic acid) was performed by ChemCon GmbH (Freiburg, Germany). The structure of the compound was initially described by Dayam R et al. [11]. AV-398/38 was dissolved and stored as a stock solution at $2.5 \mathrm{mM}$ in DMSO. Cilengitide (EMD 121974) was kindly provided by G. Prager (Medical University Vienna) or purchased from Selleckchem (Munich, Germany). (S)-(+)- camptothecin (CPT), Nutlin-3 and staurosporine (STS) were purchased from Sigma-Aldrich (Vienna, AUT) and dissolved in DMSO and stored as a stock solution at the following concentrations: $10 \mathrm{mg} / \mathrm{ml}, 54 \mu \mathrm{g} / \mathrm{ml}$, $1 \mathrm{mg} / \mathrm{ml}$ and $1 \mathrm{mg} / \mathrm{ml}$, respectively.

\section{Cell lines, reagents and antibodies}

Normal human umbilical vein endothelial cells (HUVEC), human lung microvascular endothelial cells (HMVEC-LBl), human dermal microvascular endothelial cells (HMVEC-d) and human lymphatic microvascular endothelial cells (HMVEC-dLy) were purchased from Lonza (Walkersville, MD, USA) and maintained as suggested by the manufacturer. Cells were used between passages 2 and 6. Human breast adenocarcinoma cell lines: MCF-7 was cultured in RPMI1640, MDA-MB 468 in Leibovitz L-15 medium and SKBR-3 in McCoy's $5 \mathrm{~A}$ medium. Cell lines were obtained from ATCC (American Type Culture Collection, Manassas, VA, USA). The hepatocellular carcinoma cell line HepG2, cervical carcinoma cell line HeLa and colorectal adenocarcinoma cell line HT-29 were maintained in DMEM medium and obtained from ATCC. Ewing's sarcoma cell lines T32 and T71 were kindly provided by Dr. Poul Sorensen (UBC, Vancouver, CAN) and cultured in RPMI1640 medium (1\% L-glutamine). Human squamous cell carcinoma cell lines SCC-9, SCC-25, and FaDu were kindly provided by Dr. Dietmar Turnher (Vienna Medical University, Vienna) and cultured in RPMI1640 medium. Human gastric cancer cell line N87 (from ATCC) was grown in RPMI1640 medium. Isogenic human colorectal carcinoma cell lines RKO (p53+/+, p53-/-) and HCT116 (p53+/+, p53-/-) were purchased from Horizon Discovery Ltd. (Cambridge, UK) and maintained in McCoy's 5A medium supplemented with $10 \%$ fetal bovine serum, $1 \%$ Pen-Strep and $2 \mathrm{mM}$ L-glutamine. If not indicated otherwise, all media used for cancer cell lines were supplemented with $10 \%$ fetal calf serum (Gibco, Grand Island, NY, USA) and 1\% penicillin-streptomycin (Gibco, Grand Island, NY, USA). Except for MDA-MB 468 cells, all cells were cultured at $37^{\circ} \mathrm{C}$ in a humidified $\left(5 \% \mathrm{CO}_{2}, 95 \% \mathrm{O}_{2}\right)$ air incubator.

\section{Cytotoxicity assays}

Cells were cultured in 24-well plates for 24 hours and treated with the drugs as indicated. After 72 hours incubation, the number of viable cells was determined by trypan blue exclusion and analyzed with a Vi-CEL ${ }^{\text {Tx }}$ XR Coulter counter (Beckman Coulter, Inc. Vienna, AUT). Potential solvent dependent (DMSO-induced) effects were determined in respective control experiments (data not shown). Cytotoxic activity was determined by analysis of dose-response growth curves and defined according to the calculated $\mathrm{IC}_{50}$ values.

\section{Adhesion and cellular morphology}

Endothelial cells were cultured in uncoated 24-well plates in standard growth medium for 24 hours. Cells were then exposed to the compounds at different concentrations for 20 hours. DMSO control experiments were performed to ensure that observed effects are not attribuTable to the vehicle (data not shown). Effects on cell number, adhesion and morphology were analyzed with a Vi-CEL ${ }^{\mathrm{m}} \mathrm{XR}$ Coulter counter and an Olympus IX71 inverted microscope coupled to a camera system (Olympus Color View III) at 10-fold magnification.

In short-term adhesion assays, 24 -well plates were pre-coated in duplicates with vitronectin $(2.5 \mu \mathrm{g} / \mathrm{ml})$ or fibronectin $(10 \mu \mathrm{g} / \mathrm{ml})$. After coating, potential unspecific binding sites were saturated with $0.5 \%$ BSA. HUVECs $\left(12.5 \times 10^{4}\right.$ cells/well $)$ were seeded in serum-free medium with AV-38/398 $(1 \mu \mathrm{M})$ or cilengitide $(5 \mu \mathrm{M})$. Adhesion was quantified and documented after 45 minutes. Cells were seeded in 96-well plates pre-coated with vitronectin $(2.5 \mu \mathrm{g} / \mathrm{ml})$ or fibronectin $(10 \mu \mathrm{g} / \mathrm{ml})$, treated as described above, and analyzed with an MTTbased cell viability assay according to the protocol provided by the manufacturer (EZ4U, Biomedica, Vienna, AUT).

\section{Cell migration}

Cell migration assays were performed in 24-well Costar Transwell ${ }^{\mathbb{R}}$ permeable supports with chambers separated by polycarbonate filters ( $8 \mu \mathrm{m}$ pore size). Bottom surfaces of the chamber were coated with collagen I $(3.3 \mu \mathrm{g} / \mathrm{ml})$ to support attachment of migrated cells. HUVECs $\left(6 \times 10^{4}\right.$ cell/well) were treated with compounds AV-38/398 ( 2 and $4 \mu \mathrm{M})$ or with cilengitide $(10 \mu \mathrm{M})$ and seeded in EGM-2 medium supplemented with $1 \%$ FBS into upper compartment. EGM2 endothelial cell medium conditioned with $10 \%$ FBS and $1 \%$ VEGF was added to each well on the bottom side of the chamber. HUVECs that transmigrated were fixed in ice-cold methanol and stained with $0.5 \%$ crystal violet. Stained cells were then photographed at $20 \mathrm{x}$ magnification. Migration was quantified by counting cells in four randomly selected fields. Experiments were repeated at least two times.

\section{Western blot analysis}

Cells lysates were prepared in NP-40 lysis buffer (Invitrogen, Carlsbad, CA, USA) supplemented with phosphatase inhibitor cocktail from Sigma-Aldrich (Buchs, Switzerland) and with phenylmethanesulfonyl fluoride. Protein concentrations were determined as suggested by the manufacturer (DC Protein Assay, 
Bio-Rad Laboratories, CA, USA). Proteins were resolved by sodium dodecyl sulfate-polyacrylamide gel electrophoresis (SDS-PAGE) and blotted onto nitrocellulose (Whatman, Dassel, Germany) or PVDF (Merck Millipore Ltd. Tullagreen, Carrigtwohill, Irland) membranes. Gel loading and transfer of proteins was controlled by staining of the membranes with Ponceau S (SERVA, Heidelberg, Germany). Membranes were blocked with 5\% skimmed milk in $1 \mathrm{X}$ TBS-T. The following primary antibodies were used: Anti-integrin $\alpha \mathrm{V}$, anti-integrin $\beta 3$, anti- integrin $\beta 5$, anti-Akt, anti-pAkt (Ser473), anti-FAK, anti-pFAK (Tyr925), anti-ERK1/2, anti-pERK1/2, anticleaved caspases $-3,-7,-8$ and -9 , anti-caspase -3 , anti-PARP, antiBcl-2, anti-Mcl-1, anti-Bax, anti-cyclin B1, anti-cdc2 (CDK1), anti-p cdc2 (Tyr15) (pCDK1 (Tyr15)), anti-Cdc25C, anti-pCdc25C (Ser216), anti-pChk1 (Ser296), anti-pChk2 (Thr68), anti-pBcl-2 (S70), anti-GPDH, and anti- $\alpha$ Tubulin. Antibodies were purchased from Cell Signaling Technology, Inc. (Danvers, MA, USA) and used at 1:1000 dilutions. Hybridization with HRP coupled anti-mouse or anti-rabbit secondary antibodies (Cell Signaling Technology, Inc., Danvers, MA, USA) was done at the dilution of 1:2000. Detection of the immune complexes was performed with the ECL (enhanced chemiluminescence system) from Roche Diagnostics (Indianapolis, IN, USA) according to manufacturer's protocol. FITC monoclonal anti-CD51/CD61 and FITC IgGk isotype control antibodies were obtained from Biosciences Pharmingen (San Diego, CA, USA). FITC monoclonal anti-integrin alphaVbeta5 antibody was purchased from Millipore (Volketswil, Switzerland).

\section{Cell viability assay}

HUVECs were seeded on uncoated $10 \mathrm{~cm}^{2}$ culture dishes in complete growth medium. Subconfluent cells were incubated with the compounds. Cells viability determinations were performed after $4,8,16$ and 24 hours incubation with drugs by automated trypan blue dye exclusion (Beckman Coulter Vi-CELL XR automated cell viability assay). Detached cells were collected separately and immediately counted. Adherent cells were washed with HEPES-buffered saline solution (HBSS), trypsinised, neutralized with TNS (Lonza, MD, USA), recovered by centrifugation, resuspended in standard growth medium and analyzed.

\section{Apoptosis assays}

Adherent and detached cells were collected after treatment, washed with ice-cold PBS, fixed in methanol for $10 \mathrm{~min}$ and incubated at $37^{\circ} \mathrm{C}$ for 20 min with Hoechst 33342 diluted in $0.2 \%$ Triton/PBS to a final concentration of $10 \mu \mathrm{g} / \mathrm{ml}$. Cells were then washed in PBS, and fixed in Fluoprep mounting medium (BioMérieux, Marcy I’Etoile, France). Quantitative evaluation (at $20 \mathrm{x}$ magnification) of digital images was based on manual counting of stained nuclei. The percentage of cell death in adherent and detached cells was determined as the number of apoptotic nuclei in relation to the total number of nuclei per image field. At least five images for each data point were analyzed. Each experiment was performed three times.

For the assessment of apoptosis, a sandwich immunoassay (Cell Death Detection ELISA, Roche Molecular Biochemicals, and Mannheim, Germany) was carried out to detect nucleosomes released into the cytoplasm as a consequence of DNA fragmentation. Briefly, HUVECs were cultured to $80 \%$ confluence and treated with $0.5,1$ or $4 \mu \mathrm{M}$ AV-38/398 or $1 \mu \mathrm{M}$ camptothecin (CPT). CPT was used as a positive control for the induction of apoptosis. After 18 hours incubation, adherent, and detached cells were collected separately and resuspended $\left(1 \times 10^{5}\right.$ cells $\left./ \mathrm{ml}\right)$ in lysis buffer for $30 \mathrm{~min}$. Cell debris and nuclei were pelleted at $200 \mathrm{~g}$ for $10 \mathrm{~min}$. The supernatant containing cytoplasmic apoptotic DNA was collected, and cell death was quantified according to the manufacturer's protocol.

\section{FACS analysis}

Cell surface $\alpha v \beta 3$ and $\alpha v \beta 5$ integrin receptors were detected using CD51/CD61 and $\alpha v \beta 5$ FITC-labelled antibodies at the dilutions recommended by the supplier. Cells were detached with Accutase $^{\circledR}$ solution (Sigma-Aldrich) and washed twice in PBS containing $\mathrm{Ca}^{2+}$ and $\mathrm{Mg}^{2+} / 0.1 \% \mathrm{NaN}_{3} .1 \times 10^{6}$ cells per experiment were incubated with respective antibodies or isotype controls diluted in PBS containing $\mathrm{Ca}^{2+}$ and $\mathrm{Mg}^{2+} / 0.1 \% \mathrm{NaN}_{3} / 2 \%$ FBS for $30 \mathrm{~min}$ on ice. After incubation, labeled cells were washed and analyzed with by flow cytometry (FACS Calibur, Becton-Dickinson, Franklin Lakes, NJ). To evaluate the onset of apoptotic events, fluorescein isothiocyanate (FITC)-conjugated Annexin V (Apoptosis Detection Kit, BD Biosciences) and propidium iodide (PI) double staining was performed. HUVECs were cultured on $6 \mathrm{~cm}^{2}$ plates in complete growth medium. Sub-confluent cells were treated with of NC $(0.5,1$, and $4 \mu \mathrm{M})$, cilengitide $(5 \mu \mathrm{M})$, and STS $(0.28 \mu \mathrm{M})$ for $5 \mathrm{~h}$. Staurosporine was used as a positive control for the induction of early apoptosis. After treatment, cells were suspended $\left(1 \times 10^{5}\right.$ per sample) in $100 \mu \mathrm{l}$ of $1 \mathrm{x}$ Annexin binding buffer. Subsequently, $5 \mu \mathrm{l}$ Annexin $\mathrm{V}$ and $5 \mu \mathrm{l}$ PI were added to reach end concentration of $0.5 \mu \mathrm{g} / \mathrm{ml}$ and incubated for $30 \mathrm{~min}$ on ice. After staining, $400 \mu \mathrm{l}$ of $1 \mathrm{x}$ Annexin Binding Buffer was added to each sample and cells were analyzed by FACS with CellQuest Pro ${ }^{\mathrm{m} w}$ software (Becton-Dickinson). Changes in mitochondrial membrane potential that occur during apoptosis were assessed by staining with JC-1 (5',6,6'-tetrachloro-1,1',3,3'-tetraethylb enzimidazolylcarbocyanine iodide; MitoProbe ${ }^{\mathrm{Tn}}$ JC-1 Assay Kit for Flow Cytometry, Molecular Probes ${ }^{\circledR}$ - Life Technologies, Vienna, AUT). Briefly, HUVECs were seeded in $6 \mathrm{~cm}^{2}$ plates in growth medium. After 24 hours of recovery, cells were treated with 1 , or 4 $\mu \mathrm{M} \mathrm{AV}-38 / 398,5 \mu \mathrm{M}$ cilengitide or $0.28 \mu \mathrm{M}$ STS for 5 hours. Cells were collected, pelleted, suspended at the density of $1 \times 10^{6} \mathrm{cells} / \mathrm{ml}$ per sample and incubated with JC-1 solution for $20 \mathrm{~min}$ at $37^{\circ} \mathrm{C}$. CCCP (carbonyl cyanide 3 chlorophenylhydrazone) was used as a positive control for JC-1 sensitivity. The shift of JC-1 dependent fluorescence from red in normal cells to green in damaged cells was determined by FACS and quantified with CellQuest Pro ${ }^{\text {Tx }}$ software.

\section{Cell cycle analysis}

Cell cycle distribution was analyzed by flow cytometry. After treatment with AV-38/398 (1 and $4 \mu \mathrm{M})$, cilengitide $(10 \mu \mathrm{M})$ or staurosporine $(0.28 \mu \mathrm{M})$, adherent and detached cells were collected, fixed in $70 \%$ ethanol and stored at $-20^{\circ} \mathrm{C}$ overnight. Cell pellets were suspended in $500 \mu \mathrm{l} \mathrm{PBS}$ and incubated with RNase $(10 \mu \mathrm{g} / \mathrm{ml})$ at $37^{\circ} \mathrm{C}$ for 30 minutes. Subsequently, $1 \mathrm{mg} / \mathrm{ml}$ propidium iodide (PI) was added to the solution at $4^{\circ} \mathrm{C}$ for 30 minutes. Cell cycle analysis was done with ModFit LT software (Becton-Dickinson).

\section{P53 status-dependent effects}

HCT116 (p53+/+, p53-/-, p53 mut) and RKO (p53+/+, p53-/-, 
p53 mut) colon cancer cell lines were seeded in 24-well plates ( $3 \mathrm{x}$ $10^{4}$ cells $/ \mathrm{ml}$ ) in complete growth medium. After 24 hours, cells were exposed to increasing concentrations of compound $\mathrm{AV}$, cilengitide or Nutlin-3 for 72 hours. Nutlin-3 is known to antagonize MDM2-p53 interaction and was used as a positive control.

\section{Statistical analysis}

All data are presented as mean \pm standard error of the mean (SEM). Each experiment was repeated at least two times. Statistical analyzes of differences between the means of groups were conducted using one-way ANOVA with GraphPad Prism 5.04.

\section{Results}

\section{Compound AV-38/398 displays direct anti-neoplastic effects against different cell types}

To determine the spectrum of anti-cancer activity of compound AV-38/398, we first examined its efficacy against a panel of cancer cell lines as well as primary endothelial cells. Concentration-dependent growth inhibitory effects $\left(\mathrm{IC}_{50}\right.$ values) were determined for each cell line from dose-response curves after 72 hours of treatment (Table 1). Additionally, we compared AV-38/398 activity with cilengitide. Our study revealed a broad range of anti-neoplastic effects of compound AV-38/398 on nearly all tested cell lines. Primary endothelial cells (HUVEC, HMVEC-d, HMVEC-dLy, and HMVEC-LBl) displayed

Table 1: AV-38/398 cytotoxic effects on endothelial cells and cancer cell lines. IC50 values for cell lines originating from different tumor entities and different types of human endothelial cells. IC50 values were obtained after 72 hours incubation with AV-38/398 or cilengitide from at least three independent experiments. N.d.: not determined.

\begin{tabular}{|c|c|c|c|c|}
\hline Cell Line & Origin & Histology & $\begin{array}{l}\text { AV-38/398 } \\
\text { IC }_{50} \text { (UM) }\end{array}$ & $\begin{array}{c}\text { Cilengitide } \\
\mathrm{IC}_{50}(\mathrm{UM})\end{array}$ \\
\hline HUVEC & Umbilical Vein & Endothelial & 0.3 & 2.7 \\
\hline HMVEC LBI & Microvascular & Endothelial & 0.7 & 4.3 \\
\hline HMVEC dLy & Lympatic & Endothelial & 0.7 & $>10$ \\
\hline HMVECd & Dermal & Endothelial & 0.7 & $>10$ \\
\hline FaDu & Pharnyx & $\begin{array}{l}\text { Squamous cell } \\
\text { Carcinoma }\end{array}$ & 0.9 & $>10$ \\
\hline MDA-MB -468 & Breast & Adenocarcinoma & 1.2 & 4.5 \\
\hline SKBR-3 & Breast & Adenocarcinoma & 1.5 & 4.3 \\
\hline SCC-9 & Tongue & $\begin{array}{l}\text { Squamous cell } \\
\text { Carcinoma }\end{array}$ & 1.5 & $>10$ \\
\hline TC71 & Sarcoma & Ewing's Sarcoma & 1.7 & n. d. \\
\hline HeLa & Cervix & Adenocarcinoma & 1.8 & 1.9 \\
\hline SCC-25 & Tongue & $\begin{array}{l}\text { Squamous cell } \\
\text { Carcinoma }\end{array}$ & 1.9 & $>10$ \\
\hline TC32 & Sarcoma & Ewing's Sarcoma & 1.9 & n. d. \\
\hline RKO & Colon & Adenocarcinoma & 2.0 & 0.4 \\
\hline HCT116 & Colon & Adenocarcinoma & 2.6 & 10 \\
\hline N87 & Gastric & Carcinoma & 3.2 & $>10$ \\
\hline MCF-7 & Breast & Adenocarcinoma & 3.4 & 2.2 \\
\hline HepG2 & Liver & $\begin{array}{l}\text { Hepatocellular } \\
\text { Carcinoma }\end{array}$ & 4.2 & 7.5 \\
\hline HT-29 & Colon & Adenocarcinoma & $>10$ & 8.5 \\
\hline
\end{tabular}

the highest susceptibility towards compound AV-38/398, with a mean $\mathrm{IC}_{50}$ ranging from 0.3 to $0.7 \mu \mathrm{M}$. Growth inhibitory effects on cells originating from different tumor entities were observed at low micromolar concentrations with a mean $\mathrm{IC}_{50}$ below $5 \mu \mathrm{M}$ for all cell lines tested, with the exception of the HT-29 colon adenocarcinoma cell line, which was unresponsive against AV-38/398, but moderately inhibited by cilengitide.

\section{Expression of integrin $\alpha \mathrm{V} \beta 3$ and $\alpha \mathrm{V} \beta 5$}

To evaluate whether human endothelial cells expressed $\alpha \mathrm{V} \beta 3$, integrin expression were assessed by Western blotting and flow cytometry. Primary endothelial cells (HUVECs) and colon cancer cells (HT-29) were selected for further experiments because of their differing sensitivity towards AV-38/398. Expression of the subunits of $\alpha \mathrm{V} \beta 3$ and $\alpha \mathrm{V} \beta 5$ receptors was detected in HUVECs using specific antibodies (Figure 1). No evidence for expression of $\beta 3$, but for $\alpha \mathrm{V}$ and $\beta 5$ was found in HT-29 cells. Heterodimeric integrin expression analysis by FACS with provided clear evidence for an expression of both $\alpha \mathrm{V} \beta 3$ and $\alpha \mathrm{V} \beta 5$ receptors on the surface of endothelial cells. Consistent with the results obtained from Western blotting experiments, only integrin $\alpha \mathrm{V} \beta 5$ was expressed on the surface of HT29 cells (Figure 1B).

\section{AV-38/398 triggers cell detachment in monolayer cultures and inhibits adhesion and migration}

To assess in vitro effects of compound AV-38/398 and cilengitide on cell adhesion, HUVECs were cultured in standard growth medium. After allowing the cells to recover for 24 hours, of AV-38/398 (4 $\mu \mathrm{M})$ and cilengitide $(20 \mu \mathrm{M})$ were added for 20 hours. Inhibition of adhesion was observed in HUVECs treated with AV-38/398 as well as with cilengitide (Figure $2 \mathrm{~A}$ ). In contrast to the changes in cellular morphology induced by cilengitide, no morphological alterations were triggered by AV-38/398.

To further validate whether AV-38/398 efficiently hinders integrin-mediated binding to components of extracellular matrix (ECM), thereby influencing cell survival, short-term adhesion assays were performed. HUVECs were pre-incubated with AV-38/398 or cilengitide for 15 minutes and plated on vitronectin- or fibronectincoated wells. After 45 minutes of incubation, less than $50 \%$ of endothelial cells treated with AV-38/398 attached to vitronectin and less than $80 \%$ to fibronectin compared controls. Moderate inhibition of adherence was observed for endothelial cells treated with cilengitide (see Figure 2B).

We next examined the impact of AV-38/398 and cilengitide on human endothelial cell migration. Our results show that the migratory potential of endothelial cells treated with AV-38/398 at concentrations of $2 \mu \mathrm{M}$ and $4 \mu \mathrm{M}$ as well as with cilengitide at 10 $\mu \mathrm{M}$ was significantly reduced in comparison to untreated controls (Figure 2C).

The effects of AV-38/398 and cilengitide on integrin-dependent signaling pathways were further investigated. As is shown in Figure $2 \mathrm{D}$, downregulation of FAK and Erk1/2 phosphorylation was observed after detachment induced by drug treatment. Additionally, a marked decrease in phosphorylated Akt was observed after 4 hours, 
A

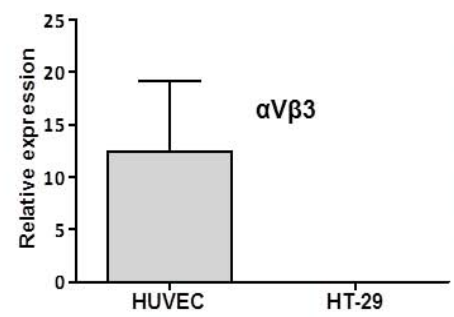

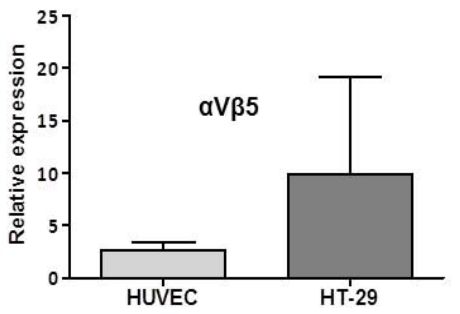

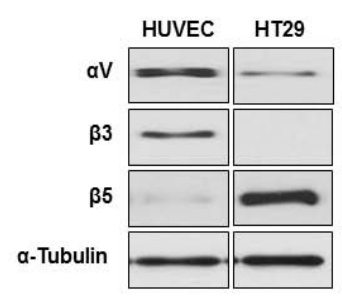

Figure 1: Expression of $\alpha \mathrm{V} \beta 3$ and $\alpha \mathrm{V} \beta 5$ in HUVECs and HT-29 cells. A: Western blot analysis of $\alpha \mathrm{V}, \beta 3$ and $\beta 5$ integrin subunits expression was carried out in untreated HUVECs and HT-29 cells cultured in full growth medium for at least 24 hours. B: Flow cytometry analysis of $\alpha \mathrm{V} \beta 3$ and $\alpha \mathrm{V} \beta 5$ heterodimer expression of untreated HUVECs and HT-29 cells (see Material and Methods).

A

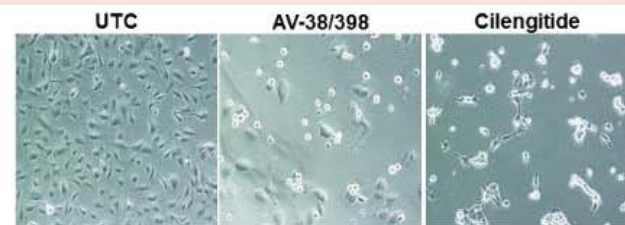

B

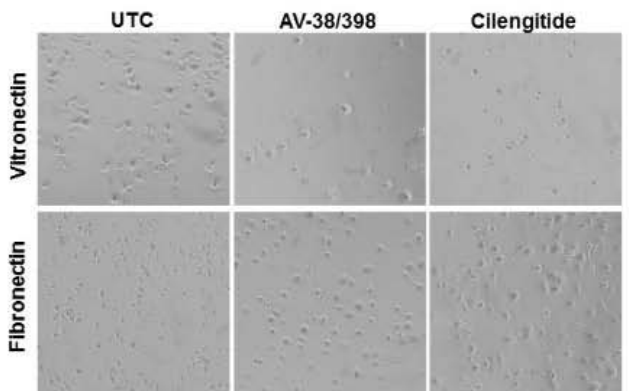

C
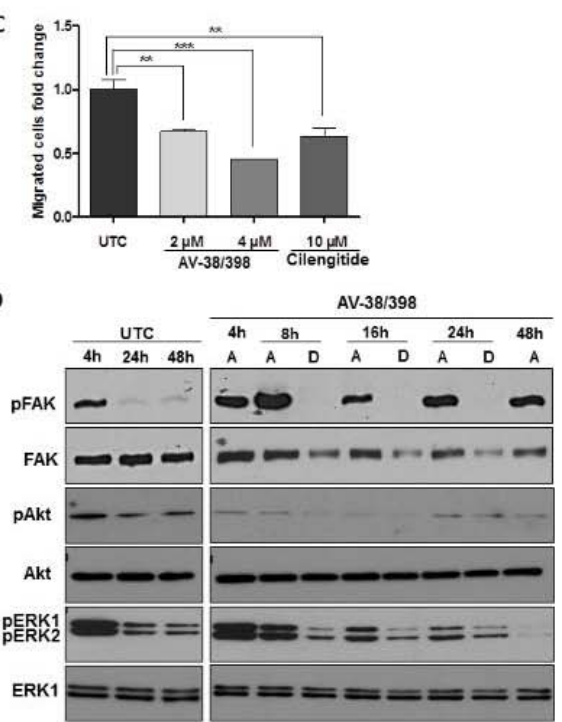

Figure 2: Analysis of cellular and morphological changes; inhibition of adhesion and migration of endothelial cells. A: Loss of cell adhesion and assessment of morphological changes in HUVECs treated with $4 \mu \mathrm{M}$ of AV-38/398 or $20 \mu \mathrm{M}$ of cilengitide in comparison to untreated control (UTC). Representative images from one of three data sets are shown. B: HUVECs adhesion to ECM integrin ligands vitronectin and fibronectin after 45 minutes exposure to $1 \mu \mathrm{M}$ AV-38/398 or $5 \mu \mathrm{M}$ cilengitide. Representative images are shown. C: Migration assay performed with HUVECs exposed to AV-38/398 $(2,4 \mu \mathrm{M})$ or cilengitide $(10 \mu \mathrm{M})$ for 5 hours as described under "Material and Methods". Trans-migrated cells were counted within four randomly chosen fields on each membrane $\left({ }^{* * *} p<0.0004\right.$; one-way ANOVA). D: Western blot analyses of FAK and pFAK (Y925), Akt and pAkt (S347), ERK and pERK 1/2 expression in adherent (A) and detached (D) HUVECs at the indicated time points. One out of three representative experiments is shown.

which remained low throughout the exposure to AV-38/398 both in adherent and detached endothelial cells.

\section{AV-38/398 treatment induces detachment of viable cells}

To investigate whether the mechanisms underlying compound AV-38/398-mediated cell growth inhibition are the consequence of the loss of cell adhesion or the result of direct cytotoxic effects, viability experiments were performed (Figure 3). As anticipated, a time-dependent decrease in cell numbers of adherent cells was shown which was accompanied by a corresponding increase in cell numbers in the floating fraction (Figure 3A, 3B). Notably, regardless of the observed cell number reduction, the percentage of viable adherent cells remained high throughout the treatment (Figure 3C).
In contrast, the viability of detached cells declined with time (Figure 3D) indicating that the effects of AV-38/398 might be associated with an initial loss of cellular attachment followed by cell death.

\section{AV-38/398 induces cell detachment leading to anoikis}

Next, we examined whether AV-38/398 triggers anoikis [12]. As is shown in Figure 4, nuclear morphological alterations corresponding to apoptosis were observed mainly in detached cells after treatment with AV-38/398. Nearly $50 \%$ of the nuclei from detached cells showed evidence for apoptosis, whereas only $5 \%$ of the cells that remained adherent during treatment with AV$38 / 398$ displayed apoptotic nuclei, a number which was similar to the percentage of apoptotic cells in untreated controls (Figure 4B). Corresponding results were obtained by cell death detection assays 
A

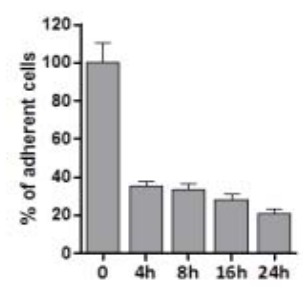

C

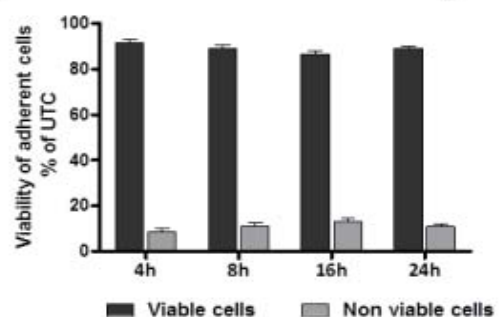

B
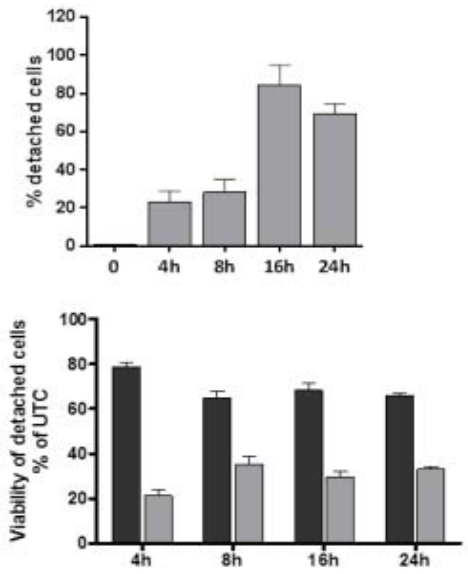

- Viable cells $\square$ Non viable cells

Figure 3: AV-38/398 induces cell detachment of HUVECs. A, B: Time dependent decrease in adherent and detached cells in the presence of $4 \mu \mathrm{M}$ of AV-38/398 for $4,8,16$ or 24 hours. C, D: Viability of adherent and detached HUVECs during treatment with $4 \mu \mathrm{M} \mathrm{AV-38/398}$ at the indicated time points. Data analysis is based on average from at least three independent experiments.
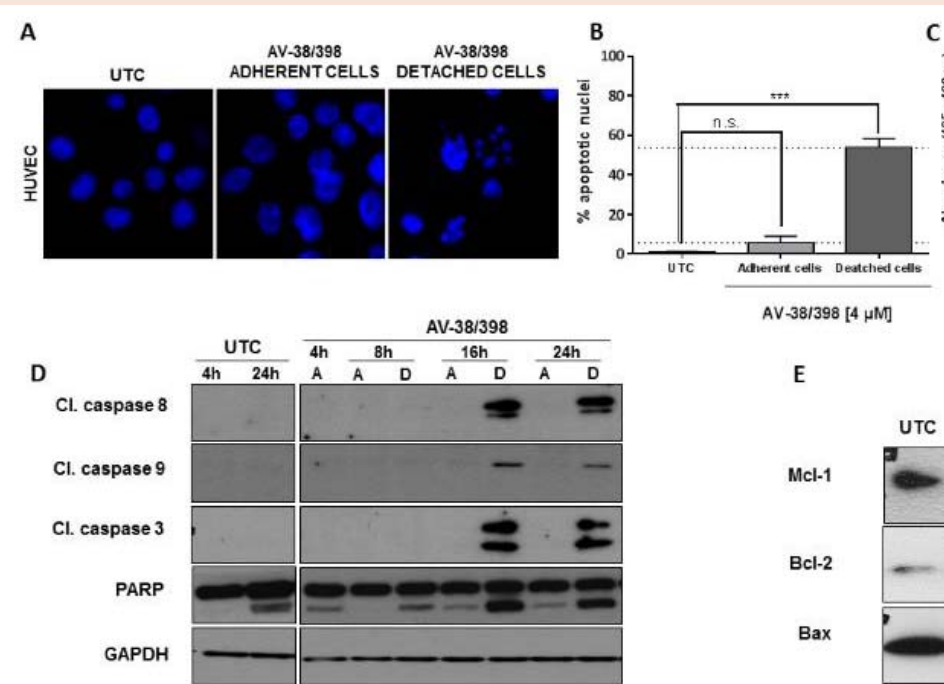

AV $-38 / 398[4 \mu \mathrm{M}]$

E

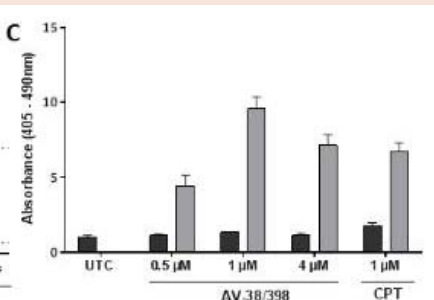

- Adher ent cells $\square$ Detached cells

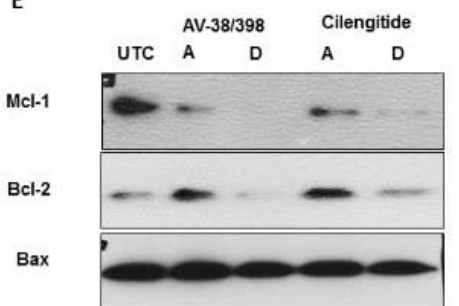

Figure 4: AV-38/398 induces anoikis in HUVECs. A: Nuclei staining with Hoechst 33342 in HUVECs showing apoptotic morphology. Cells were treated with $4 \mu \mathrm{M}$ of AV-38/398 for 18 hours. Adherent and detached cells were analyzed separately. B: Percentage of apoptotic nuclei in adherent or detached cells versus untreated adherent cells (UTC). Statistical evaluation was based on mean values of three independent experiments (*** $p<0.0001$; one-way ANOVA) C: Nucleosome analysis performed by ELISA. HUVECs were treated with AV-38/398 or Camptothecin (CPT) for 18 hours. Assessment of apoptotic DNA was separately conducted for adherent cells (dark grey) and detached cells (light grey). D: Analysis of activated caspases-3,-8, and -9, and PARP. E: Western blot analysis of Mcl-1, Bcl-2 and Bax in adherent $(A)$ and detached (D) HUVECs treated with AV-38/398 $(4 \mu \mathrm{M})$ or cilengitide $(20 \mu \mathrm{M})$.

utilized to identify nucleosomes released into the cytoplasm during apoptosis. Camptothecin (CPT), which is known to trigger apoptosis, was used as a control. A significant increase in DNA fragmentation was observed at a concentration of $0.5 \mu \mathrm{M}$ of AV-38/398 limited to detached cells (Figure 4C).

Anoikis is known to be mediated by at least two distinct cell death pathways, namely the extrinsic pathway (initiator caspase-8) and the intrinsic pathway (initiator caspase -9) [13]. Caspase -3 is an executioner caspase for both the extrinsic and intrinsic pathways. As is shown in Figure 4D, AV-38/398-induced activation of caspases-8, -9 and -3 , as well as PARP cleavage, was exclusively found in detached endothelial cells. We next investigated the expression of proteins of the Bcl-2 family by immunoblotting. A marked down-regulation (Figure 4) of the anti-apoptotic members Bcl-2 and Mcl-1 in detached endothelial cells after 18 hours treatment with AV-38/398 or with cilengitide was observed. Also, the ratio of anti-apoptotic Bcl-2 to pro-apoptotic protein Bax was reduced in detached endothelial cells providing further evidence for the activation of the apoptotic pathway (Figure 4E). We next attempted to determine the onset of 

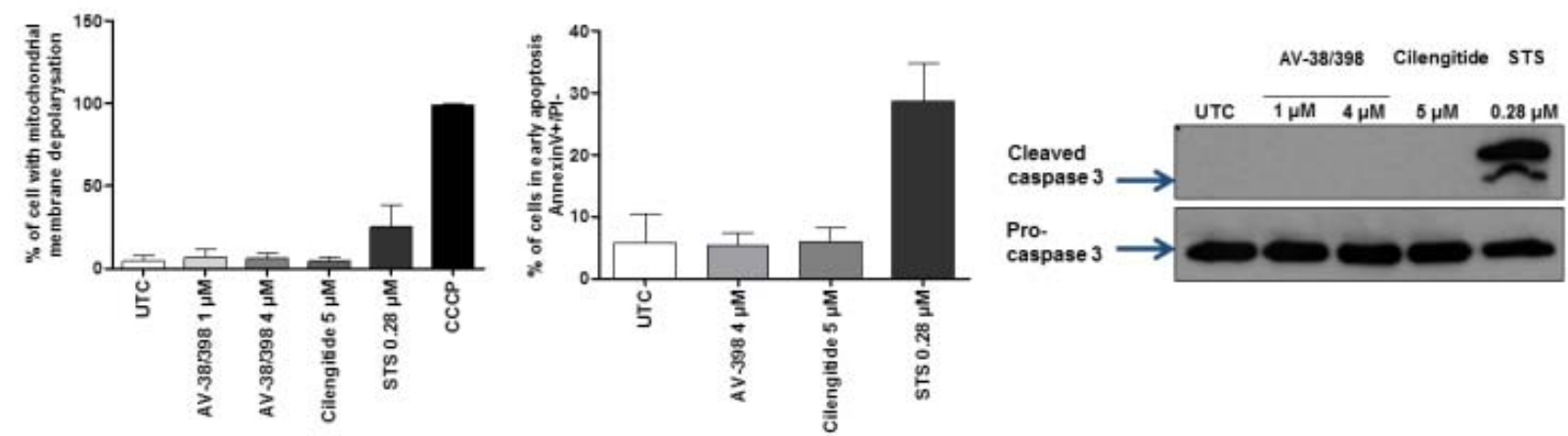

Figure 5: Determination of time of onset of early apoptosis. Evaluation of the activation of caspase-3 (right figure) and staining of Annexin V/PI or JC-1 with flow cytometry. HUVECs were treated at indicated concentrations of AV-38/398, cilengitide or STS as a positive control for 5 hours. CCCP was used as a positive control in the JC-1 staining experiment.
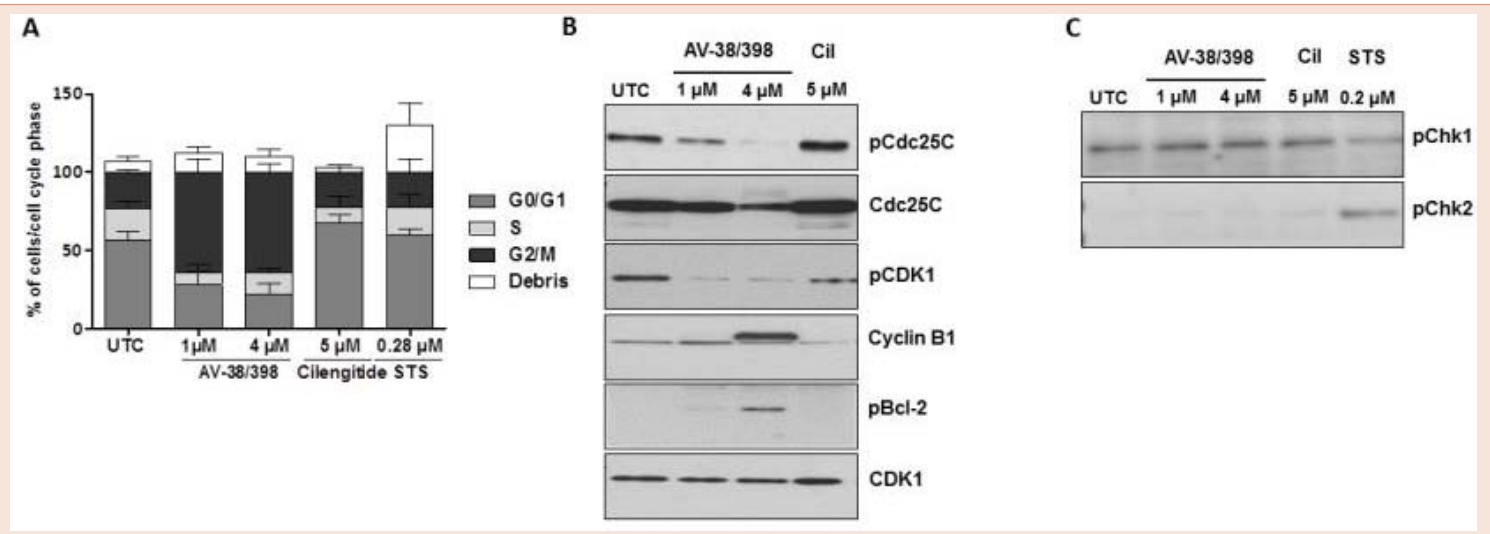

Figure 6: AV-38/398 induces G2/M phase arrest in HUVECs without evidence of DNA damage. A: FACS analysis of HUVECs treated with AV-38/398 (1 $1 \mu \mathrm{M}, 4 \mu \mathrm{M})$, cilengitide $(\mathrm{Cil})(5 \mu \mathrm{M})$ or staurosporine $(0.28 \mu \mathrm{M})$ for 18 hours. Percentages of cells in $\mathrm{G} 0 / \mathrm{G} 1, \mathrm{~S}$ and $\mathrm{G} 2 / \mathrm{M}$ phase are show. Data represent mean values of three independent experiments. B: Western blot analysis of phospho-cdc25C (Ser216), cdc25C, phospho-CDK1 (Tyr15), CDK1, and cyclin B1. C: phospho-Ch1 (Ser296) and phospho-Ch2 (Thr68) treated with STS $(0.28 \mu \mathrm{M})$ for 18 hours.
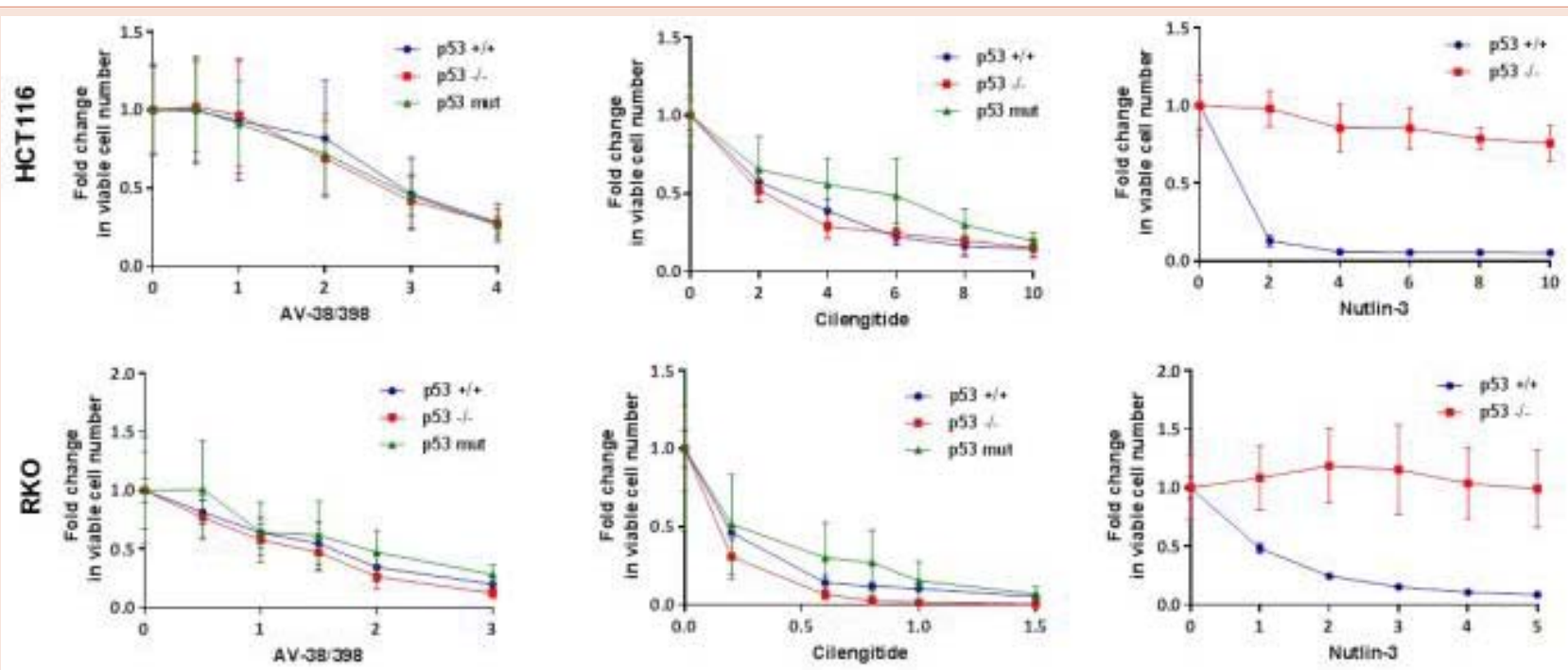

Figure 7: AV-38/398 acts independent of TP53 status. RKO (p53 +/+, p53 -/-, p53 mut) and HCT116 (p53 +/+, p53 -/-, p53 mut) colon cancer cell lines were cultured for 72 hours in the presence of increasing concentrations (in $\mu \mathrm{M}$ ) of compounds as indicated in the figures. Results are given as fold change in numbers of viable cells compared to untreated controls. Mean values of viable cell numbers from three independent experiments are presented. 
apoptosis. Therefore, FITC-AnnexinV/PI experiments, as well as JC-1 staining for detection of alterations in mitochondrial membrane potential (MMP), and analysis of caspase-3 cleavage was performed. For comparison, cilengitide was used as an integrin antagonist that triggers anoikis [14-17]. Staurosporine served as a positive control for the induction of early apoptosis [18]. Our results showed (Figure 5) no evidence for caspase -3 activation, an increased Annexin V staining, and mitochondrial membrane potential alterations before detachment of HUVECs exposed to compound AV or cilengitide.

\section{AV-38/398 induces cell cycle arrest in G2/M stage in HUVECs}

To examine potential effects of AV-38/398 on cell cycle distribution, flow cytometry evaluations were performed. For comparison, HUVECs were treated with cilengitide. As is shown in Figure 6, AV-38/398 caused a marked accumulation of human endothelial cells in $\mathrm{G} 2 / \mathrm{M}$ phase, displaying an average of $65 \%$ G2/M-phase cells compared to $23.3 \%$ G2/M control-treated cells In contrast, cilengitide treatment induced a weak arrest in G0/G1 . Noteworthy, AV-38/398-triggered G2/M arrest was accompanied by a decrease of cells in G1 phase, as well as of cells in S phase, whereas G0/G1 arrest by cilengitide was associated with a decline in S phase population (from $20 \%$ to $10 \%$ ).

Next, we investigated the expression patterns of cell cycle progression regulators involved in G2/M transition. As is shown in Figure 6, AV-38/398 treatment of HUVECs resulted in decreased phosphorylation of the inactivating phosphorylation-site of CDK1 at Tyr15 and increased levels of cyclin B1. Likewise, a minor reduction in total $\mathrm{Cdc} 25 \mathrm{C}$ protein expression at $4 \mu \mathrm{M}$ drug concentration was consistent with the marked decrease in phosphorylation of Cdc25C at Ser216. Additionally, a concentration-depended increase in phosphorylation of Bcl-2 at Ser70 was observed in cells treated with AV-38/398. No activation of the check point kinases Chk1 (at Ser296) and Chk2 (at Thr68) was detected. HUVECs exposed to cilengitide showed no accumulation of cyclin B1 or an increase of phosphorylation of CDK1 (Tyr15) or Cdc25C (Ser216).

\section{AV-38/398 effects do not depend on TP53}

To assess whether the effects of AV-38/398 depend on p53 status, two isogenic colon cell lines (HCT116 and RKO) displaying different p53 status were selected (p53 +/+, p53-/- and p53 mutated, respectively). TP53 expression and mutation status were verified by Western blot analysis (data not shown). Our data presented in Figure 7 revealed that the p53 status in both examined cell lines had no impact on the efficacy of AV-38/398. In agreement with the previously reported p53 status independence of cilengitide $[19,20]$, no influence on its efficacy was observed in our experiments. Nutlin-3 was used as an active control and displayed marked p53 status dependency. As expected, p53 wild-type cells were highly sensitive to Nutlin-3, whereas $\mathrm{p} 53 /$ null cells were non-responsive.

\section{Discussion}

The urge to shift the balance from conventional chemotherapy towards more selective and efficient approach with less toxicity to healthy cells has intensified the efforts to develop integrintargeting drugs. Previous studies on integrin expression and activity patterns revealed marked association of integrin $\alpha \mathrm{V} \beta 3$ with cancer invasion, metastasis, angiogenesis and poor prognosis [6,21,22]. We performed a comprehensive evaluation of the effects of a novel integrin antagonist in comparison with cilengitide in a panel of cancer cell lines and normal human endothelial cells. In agreement with our experimental data, the magnitude of susceptibility to AV$38 / 398$ correlated with the expression of integrin $\alpha \mathrm{V} \beta 3$. We show that $\alpha \mathrm{V} \beta 3$-expressing human endothelial cells demonstrated the highest sensitivity against $\mathrm{AV}-38 / 398$ with $\mathrm{IC}_{50}$ in the nanomolar range, whereas HT-29 adenocarcinoma cells, lacking $\alpha \mathrm{V} \beta 3$, were non-responsive to the treatment. Since HT-29 is devoid of integrin $\alpha \mathrm{V} \beta 3$ expression but is positive for $\alpha \mathrm{V} \beta 5$ [23,24; see data Figure 1], we compared AV-38/398 effects towards the $\alpha \mathrm{V} \beta 3 / \alpha \mathrm{V} \beta 5$ integrin antagonist cilengitide. Cilengitide effectively inhibited the growth of HT-29 cells but was less efficient in endothelial cells. The lower activity of cilengitide compared to AV-38/398 may be attributed to the reduced expression of integrin $\alpha \mathrm{V} \beta 5$ observed in endothelial cells grown in vitro $[15,25]$ and suggests that the activity of cilengitide requires both $\alpha \mathrm{V} \beta 3$ and $\alpha \mathrm{V} \beta 5$ as a target for full efficacy.

Data obtained from cell adhesion assays demonstrate that AV38/398 triggers dose-dependent effects on endothelial cells leading to detachment. Analysis of cellular morphology after exposure to AV-38/398 showed no alterations in the appearance of attached endothelial cells. In contrast, cells treated with cilengitide revealed morphological changes similar to those described by others [14]. AV-38/398 significantly inhibited adhesion of endothelial cells to vitronectin-coated plates, which is known to bind to $\alpha \mathrm{V} \beta 3$. However, only moderate effects on endothelial cell adhesion in the presence of fibronectin-coated dishes were seen in the presence of AV-38/398 or cilengitide. These observations may be explained by a preference of human umbilical endothelial cells to attach to fibronectin via integrin $\alpha 5 \beta 1[26,27]$. Also, we observed a clear expression of $\alpha 5$ and $\beta 1$ in HUVECs used in our study (data not shown). These observations underline that AV-38/398 significantly impairs cell adhesion to ECM components, particularly when mediated via integrin $\alpha \mathrm{V} \beta 3$.

As reported elsewhere, adequate interactions of cells with the extracellular matrix are crucial for many cellular functions that, besides survival and proliferation, also involve migration and invasion. The expression of integrin $\alpha \mathrm{V} \beta 3$ has been shown to have a considerable impact on the migratory and invasive potential of different cell types [28-30]. Overexpression of $\alpha \mathrm{V} \beta 3$ was reported to be associated with enhanced invasiveness in some cancer types such as melanoma [31] or breast cancer [32], as well as with an increased migratory potential of endothelial cells during angiogenesis [33]. Experimental data obtained from transmembrane migration assays revealed that AV-38/398 suppresses migration of endothelial cells in a dose-dependent manner. Western blotting experiments clearly showed a decrease in the activation state integrin-linked signaling pathways involved in cell migration and proliferation, such as FAK, Akt, and ERK1/2 [30,34]. Our results partially overlap with those reported for cilengitide in HUVECs [14]. These findings demonstrate the ability of AV-38/398 to inhibit effectively cell adhesion and migratory potential, both of which are critical for cancer spreading and infiltration of remote tissues.

Further analysis of adhesion and viability dynamics in endothelial cells exposed to AV-38/398 demonstrated time- and dose-dependent effects on detachment without measurable effects on cellular 
viability on the adherent cell fraction. In contrast, to the adherent cell population, the analysis of floating HUVECs revealed a timedependent increase in the number of cells displaying apoptotic morphology accompanied by an activation of caspases $-3,-8,-9$ and PARP cleavage. Similar results were previously reported about the RGD (Arg-Gly-Asp)-mimetic antagonist S 36578-2 [35]. Changes in the expression pattern of Bcl-2 family proteins were reported to be linked to a propensity towards induction of anoikis [36]. Our experiments showed that treatment with AV-38/398 is associated with reduced levels of the anti-apoptotic proteins Bcl-2 and Mcl-1, as well as a decrease in the Bcl-2 to Bax ratio, favoring susceptibility to apoptotic cell death. Of note, no signs of an onset of apoptosis were detected before the detachment of endothelial cells induced by AV-38/398 treatment. Based on these findings, we propose anoikis as the fundamental mechanism responsible for the anti-neoplastic activity of the compound. Interestingly, we could not detect any clear experimental evidence for induction of anoikis by cilengitide.

Apoptosis and cell cycle progression are shown to be coupled [37-39]. Recent studies reported that cell cycle arrest in G1 or G1/S phase may be linked to resistance to anoikis $[40,41]$. Flow cytometry analyzes demonstrated that AV-38/398 triggers a marked increase in the G2/M fraction and a parallel decrease in G0/G1 and S phase cells. A decline in G1 and S-phase cells, in combination with changes in the activation state of cycle regulators, indicate a progression through the cell cycle. Additionally, expression patterns of proteins regulating G2/M progression demonstrated activation of CDK1 and increase in the expression of cyclin $\mathrm{B} 1$, events that are related to transition into mitotic stage [42]. We observed, in AV-38/398 treated cells, phosphorylation of Bcl-2 on Ser70, which was reported to be a marker for mitotic arrest [43]. In summary, these findings indicate that HUVECs treated with AV-38/398 progress through the cell cycle until the activation of G2/M transition complex CDK1-cycline B1 and accumulated in the early $\mathrm{M}$ phase of mitosis.

The tumor suppressor protein TP53 is known to play a crucial role in the control of apoptosis. We, therefore, investigated the potential influence of TP53 status on the efficacy, as determined by survival effects, of AV-38/398 as well as cilengitide. Our results obtained from the experiments with two colon cancer cell lines (HCT116 and RKO), each with a differently altered TP53 status (p53+/+, p53-/- or p53 mut), revealed no effect of the TP53 on survival.

In conclusion, our results demonstrate that a novel $\alpha \mathrm{V} \beta 3$ integrin antagonist AV-38/398 acts via triggering anoikis. Our data indicate that structures based on the chemistry of AV-38/398 may be considered promising drug candidates for selectively and more successfully targeting cancer cells and diseases associated with pathologically activated vascular growth.

\section{Acknowledgment}

The authors would like to thank R. Hoffmann (Department Radiation Oncology - Medical University of Vienna, Austria) for the technical assistance in the project. The authors are also indebted to Mrs. Herbacek from the Institute of Cancer Research (Medical University of Vienna) for the technical support with FACS analysis.

\section{Competing interest}

E.S. has received scientific grants from Merck GmbH (Austria).

\section{References}

1. Millard M, Odde S, Neamati $N$ (2011) Integrin targeted therapeutics. Theranostics 1: 154-188.

2. Boudreau NJ, Jones PL (1999) Extracellular matrix and integrin signalling: the shape of things to come. Biochem J 339: 481-488.

3. Giancotti F G (2000) Complexity and specificity of integrin signalling. Nat Cell Biol 2: 13-14.

4. Bouvard D, Pouwels J, De Franceschi N, Ivaska J (2013) Integrin inactivators: balancing cellular functions in vitro and in vivo. Nat Rev Mol Cell Biol 14: 430442.

5. Goodman SL, Picard M (2012) Integrins as therapeutic targets. Trends Pharmacol Sci 33: 405-412.

6. Desgrosellier JS, Cheresh DA (2010) Integrins in cancer: biological implications and therapeutic opportunities. Nat Rev Cancer 10: 9-22.

7. Bell-McGuinn KM, Matthews CM, Ho SN, Barve M, Gilbert L, et al. (2011) A phase II, single-arm study of the anti-alpha5beta1 integrin antibody volociximab as monotherapy in patients with platinum-resistant advanced epithelial ovarian or primary peritoneal cancer. Gynecol Oncol 121: 273-279.

8. Hersey P, Sosman J, O'Day S, Richards J, Bedikian A, et al. (2010) A randomized phase 2 study of etaracizumab, a monoclonal antibody against integrin alpha(v)beta(3) + or - dacarbazine in patients with stage IV metastatic melanoma. Cancer 116: 1526-1534.

9. Nabors LB, Fink KL, Mikkelsen T, Grujicic D, Tarnawski R, et al. (2015) Two cilengitide regimens in combination with standard treatment for patients with newly diagnosed glioblastoma and unmethylated MGMT gene promoter: results of the open-label, controlled, randomized phase zl CORE study. Neuro Oncol 17: 708-717

10. Vansteenkiste J, Barlesi F, Waller CF, Bennouna J, Gridelli C, et al. (2015) Cilengitide combined with cetuximab and platinum-based chemotherapy as first-line treatment in advanced non-small-cell lung cancer (NSCLC) patients: results of an open-label, randomized, controlled phase II study (CERTO). Ann Oncol 26: 1734-1740.

11. Dayam R, Aiello F, Deng J, Wu Y, Garofalo A, et al. (2006) Discovery of small molecule integrin alphavbeta3 antagonists as novel anticancer agents. J Med Chem 49: 4526-4534.

12. Frisch SM, and Ruoslahti E (1997) Integrins and anoikis. Curr Opin Cell Bio 9: 701-706.

13. Gilmore AP (2005) Anoikis. Cell Death Differ. 12 (Suppl 2): 1473-1477.

14. Oliveira-Ferrer L, Hauschild J, Fiedler W, Bokemeyer C, Nippgen J, et al. (2008) Cilengitide induces cellular detachment and apoptosis in endothelial and glioma cells mediated by inhibition of FAK/src/AKT pathway. J Exp Clin Cancer Res 27: 86.

15. Alghisi GC, Ponsonnet L, Ruegg C (2009) The integrin antagonist cilengitide activates alphaVbeta3, disrupts VE-cadherin localization at cell junctions and enhances permeability in endothelial cells. PloS One 4: e4449.

16. Cheng NC, van Zandwijk N, and Reid G (2014) Cilengitide inhibits attachment and invasion of malignant pleural mesothelioma cells through antagonism of integrins alphavbeta3 and alphavbeta5. Plos One 9: e90374.

17. Leblond P, Dewitte A, Le Tinier F, Bal-Mahieu C, Baroncini M, et al. (2013) Cilengitide targets pediatric glioma and neuroblastoma cells through cell detachment and anoikis induction. Anticancer drugs 24: 818-825.

18. Zhang XD, Gillespie SK, Hersey P (2004) Staurosporine induces apoptosis of melanoma by both caspase-dependent and -independent apoptotic pathways. Mol Cancer Ther 3: 187-197.

19. Weller M, Rieger J, Grimmel C, Van Meir EG, De Tribolet N, et al. (1998) Predicting chemoresistance in human malignant glioma cells: the role of molecular genetic analyses. Int J Cancer 79: 640-644.

20. Maurer GD, Tritschler I, Adams B, Tabatabai G, Wick, et al. (2009) Cilengitide modulates attachment and viability of human glioma cells, but not sensitivity to irradiation or temozolomide in vitro. Neuro Oncol 11: 747-756. 
21. Zheng DQ, Woodard AS, Tallini G, and Languino LR (2000) Substrate specificity of alpha(v)beta(3) integrin-mediated cell migration and phosphatidylinositol 3-kinase/AKT pathway activation. J Bio Chem 275: 24565-24574.

22. Reinmuth N, Liu W, Ahmad SA, Fan F, Stoeltzing O, et al. (2003) Alphavbeta3 integrin antagonist S247 decreases colon cancer metastasis and angiogenesis and improves survival in mice. Cancer Res 63: 2079-2087.

23. Mitjans F, Meyer T, Fittschen C, Goodman S, Jonczyk A, et al. (2000) In vivo therapy of malignant melanoma by means of antagonists of alphav integrins. Int J Cancer. 87: 716-723.

24. Goodman SL, Grote HJ, and Wilm C (2012) Matched rabbit monoclonal antibodies against alphav-series integrins reveal a novel alphavbeta3-LIBS epitope, and permit routine staining of archival paraffin samples of human tumors. Biol Open 1: 329-340.

25. Ruegg C, Yilmaz A, Bieler G, Bamat J, Chaubert P, et al. (1998) Evidence for the involvement of endothelial cell integrin alphaVbeta3 in the disruption of the tumor vasculature induced by TNF and IFN-gamma. Nat Med 4: 408-414.

26. Conforti G, Zanetti A, Colella S, Abbadini M, Marchisio PC, et al (1989) Interaction of fibronectin with cultured human endothelial cells: characterization of the specific receptor. Blood 73: 1576-1585.

27. Wary KK, Mainiero F, Isakoff SJ, Marcantonio EE, Giancotti FG (1996) The adaptor protein Shc couples a class of integrins to the control of cell cycle progression. Cell 87: 733-743.

28. Leavesley DI, Schwartz MA, Rosenfeld M, Cheresh DA (1993) Integrin beta 1- and beta 3-mediated endothelial cell migration is triggered through distinct signaling mechanisms. J Cell Biol 121: 163-170.

29. Simon KO, Nutt EM, Abraham DG, Rodan GA, Duong LT (1997) The alphavbeta3 integrin regulates alpha5beta1-mediated cell migration toward fibronectin. J Biol Chem 272: 29380-29389.

30. Hynes RO (2002) Integrins: bidirectional, allosteric signaling machines. Cell 110: $673-687$.

31. Kuphal S, Bauer R, Bosserhoff AK (2005) Integrin signaling in malignant melanoma. Cancer Metastasis Rev 24: 195-222.

32. Felding-Habermann B, O'Toole TE, Smith JW, Fransvea E, Ruggeri ZM, et al (2001) Integrin activation controls metastasis in human breast cancer. Proc Natl Acad Sci USA 98: 1853-1858.
33. Brooks PC, Clark RA, Cheresh DA (1994) Requirement of vascular integrin alpha $v$ beta 3 for angiogenesis. Science 264: 569-571.

34. Kanaji N, Nelson A, Wang X, Sato T, Nakanishi M, et al. (2013) Differential roles of JNK, ERK1/2, and p38 mitogen-activated protein kinases on endothelial cell tissue repair functions in response to tumor necrosis factoralpha. J Vasc Res 50: 145-156

35. Maubant S, Saint-Dizier D, Boutillon M, Perron-Sierra F, Casara PJ, et al. (2006) Blockade of alpha $v$ beta3 and alpha $v$ beta5 integrins by RGD mimetics induces anoikis and not integrin-mediated death in human endothelial cells. Blood 108: 3035-3044

36. Simpson CD, Anyiwe K, Schimmer AD (2008) Anoikis resistance and tumor metastasis. Cancer Lett 272: 177-185.

37. Castedo M, Perfettini JL, Roumier T, Kroemer G (2002) Cyclin-dependent kinase-1: linking apoptosis to cell cycle and mitotic catastrophe. Cell Death Differ 9: 1287-1293.

38. Evan GI, Brown L, Whyte M, Harrington E (1995) Apoptosis and the cell cycle. Curr Opin Cell Biol 7: 825-834.

39. Nahle Z, Polakoff J, Davuluri RV, McCurrach ME, Jacobson MD et al. (2002) Direct coupling of the cell cycle and cell death machinery by E2F. Nat Cell Biol 4: 859-864.

40. Carduner L, Picot CR, Leroy-Dudal J, Blay L, Kellouche S, et al. (2014) Cell cycle arrest or survival signaling through alphav integrins, activation of PKC and ERK $1 / 2$ lead to anoikis resistance of ovarian cancer spheroids. Expe Cell Res 320: 329-342.

41. Collins NL, Reginato MJ, Paulus JK, Sgroi DC, Labaer J, et al. (2005) G1/S cell cycle arrest provides anoikis resistance through Erk-mediated Bim suppression. Mol Cell Biol 25: 5282-5291.

42. Chaudhary P, Sharma R, Sahu M, Vishwanatha JK, Awasthi S, et al. (2013) 4-Hydroxynonenal induces G2/M phase cell cycle arrest by activation of the ataxia telangiectasia mutated and Rad3-related protein (ATR)/checkpoint kinase 1 (Chk1) signaling pathway. J Biol Chem 288: 20532-20546.

43. Ling YH, Tornos C, Perez-Soler R (1998) Phosphorylation of Bcl-2 is a marker of $\mathrm{M}$ phase events and not a determinant of apoptosis. J Biol Chem 273: 18984-18991.

Copyright: (c) 2016 Christenheit A, et al. This is an open-access article distributed under the terms of the Creative Commons Attribution License, which permits unrestricted use, distribution, and reproduction in any medium, provided the original author and source are credited. 